\title{
EFFECTS OF METFORMIN PLUS GLICLAZIDE VERSUS METFORMIN PLUS GLIMEPIRIDE ON CARDIOVASCULAR RISK FACTORS IN PATIENTS WITH TYPE 2 DIABETES MELLITUS
}

\author{
Gamil M. Abd-Allah', Memy H. Hassan.,"* \\ ${ }^{1}$ Department of Biochemistry, Faculty of Pharmacy, Al-Azahr University, Cairo, Egypt. \\ ${ }^{2}$ Department of Pharmacology and Toxicology, Faculty of Pharmacy, Al-Azahr University, \\ Cairo, Egypt.
}

\begin{abstract}
High plasma glucose level, lipid profile disturbances and high plasma homocysteine (Hcy) are important risk factors for cardiovascular diseases in patients with type 2 diabetes. This study was conducted to evaluate and compare effects of glimepiride/metformin combination versus gliclazide/metformin combination on cardiovascular risk factors in type-2 diabetes mellitus (T2DM) patients. One hundred and eighty T2DM patients were randomly allocated for treatment with placebo (control), metformin (500 mg twice daily), glimepiride (3mg once daily), gliclazide (80 mg once daily), metformin plus glimepiride or metformin plus gliclazide for 3 months. We evaluated plasma levels of glucose (PG), glycated hemoglobin (HbA1C), Hcy, vitamin B12, folic acid and lipid profile before treatment and 3 months post treatment. Compared to metformin treated patients, glimepiride plus metformin induced significant reductions in: fasting plasma glucose, postprandial PG, $\mathrm{HbA} 1 \mathrm{C} \%$ and plasma Hcy level. Conversely, plasma folic acid and vitamin B12 were significantly increased. The levels of total cholesterol and triglyceride were significantly decreased; lowdensity lipoprotein was markedly decreased, whereas high-density lipoprotein was significantly increased and hence risk ratio was significantly decreased. Similar results but with lower values were obtained using combination of metformin plus gliclazide on glycemic control only. Combination of glimepiride with metformin was superior to gliclazide plus metformin in alleviating the cardiovascular risk factors in type 2 diabetes mellitus patients.
\end{abstract}

Key words: Diabetes mellitus type 2, metformin, gliclazide, glimepiride, serum homocysteine

\section{Abbreviations:}

Hcy: homocysteine; T2DM: type 2 diabetes mellitus; PG: plasma glucose; HbA1C: glycated hemoglobin; HHcy: Hyperhomocysteinemia ; WHO: World Health Organization; FPG: fasting plasma glucose; PPG: postprandial plasma glucose; BMI: body mass index; HDL: high density lipoprotein ; LDL: low density lipoprotein; ROS: reactive oxygen species

\section{INTRODUCTION}

Type 2 diabetes mellitus (T2DM) is a metabolic disorder characterized by partial or complete insulin deficiency and / or defects in insulin action (Alberti and Zimmet, 1998).Many reports have supported the use of antidiabetic combinations with complementary mechanisms of action e.g. Sulfonylurea/ metformin, to effectively control glycemia in T2DM (DeFronzo, 1999; Erle et al., 1999; Dailey, 2003; Rendell, 2004). Metformin decreases blood glucose levels by hampering liver glucose production and by sensitizing peripheral tissue to insulin. In contrast, sulfonylureas such as gliclazide and glimepiride lower hyperglycemia via increasing insulin secretion (Hermann et al., 1994). 
Although guidelines encourage the use of metformin in combination with life style modification as the first choice for T2DM (DeFronzo, 1999; Rendell, 2004; Nathan et al., 2009; Raz, 2013), unfortunately, metformin use in patients with type 2 diabetes is associated with decreased vitamin B12 and folate levels and increased level of homocysteine (Hcy) (Tomkin et al., 1971; Fonseca et al., 1999; Wulffelé et al., 2003; Sahin et al., 2007 Aghamohammadi et al., 2011). Hyperhomocysteinemia (HHcy), an elevated plasma level of homocysteine (Hcy), induces oxidative stress in type 2 diabetes (Eikelboom et al., 1999; Aghamohammadi et al., 2011). Moreover, many studies have demonstrated that increased plasma Hcy level is an important risk factor for cardiovascular diseases in patients with T2DM. (Munshi et al., 1996; Eikelboom et al., 1999; Stehouwer et al., 1999; Hoogeveen et al., 2000; Aghamohammadi et al., 2011). Many factors play a pivotal role in determining plasma Hcy concentrations. Some of these important factors include many drugs, certain hormones and of particular interest plasma levels and intake of vitamin B12 and folic acid (Naurath et al., 1995; Jacobsen, 1996; Fonseca et al., 1999; Aghamohammadi et al., 2011). Obviously, uncontrolled type 2 diabetic patients are at an increased risk of coronary heart diseases (Haffner et al., 1998). Moreover, It is still the most leading cause of cardiovascular disease (Holman et al., 2008; Raz, 2013). Although controlling hyperglycemia reduces cardiovascular risk (Cefalu, 2005; Waugh et al., 2006), there have been a great attention about utilizing sulphonylureas and metformin due to potential side effects on the heart which might induced via non specific binding of sulphonylureas to ATP sensitive potassium channel (Bell, 2006), and possible increased Hcy plasma level by metformin (Fonseca et al ., 1999; Sahin et al., 2007; Aghamohammadi et al., 2011).

The aim of this study was to compare the therapeutic effect of metformin and gliclazide versus glimepiride and metformin on glycemic control and serum levels of; HbA1C, Hcy, folate, vitamin B12, lipid profile as leading risk factor contributing for cardiovascular disorders in patients with newly diagnosed uncontrolled type 2 diabetes mellitus

\section{METHODS}

\subsection{Subjects}

All patients were recruited and diagnosed by Al-Zahra hospital staff through output patient clinic for diabetes and other clinical findings from years 2011 to 2012. The WHO/IDF consultation report of diabetes diagnostic criteria of 2006 were used for diagnoses of patients with T2DM. All selected patients had neither been diagnosed as diabetic nor treated before. The study protocol was reviewed, approved and all patients read and accept the study protocol.

The inclusion criteria were: Male, age 30-75 years, body mass index (BMI) 18.5-30 $\mathrm{kg} / \mathrm{m}^{2}$, T2DM, , FPG $150-250 \mathrm{mg} / \mathrm{dl}$ and HbA1c $7-12 \%$ at the first visit and FPG $\geq 140$ $\mathrm{mg} / \mathrm{dl}$ at the second visit, followed stable sulfonylurea, metformin or both therapy.

Exclusion criteria included: hepatic disease, kidney disorders, cardiac diseases, current sever gastrointestinal diseases which may affect the absorption of the study drugs, history of substance abuse, history of diabetes, known allergy to gliclazide, glimepiride or metformin, history of stroke, arrhythmia that required medical treatment within the past 6 months, proliferative retinopathy, concomitant infection, seriously dehydrated, or history of other investigation drug intake, operation within 4 weeks before the study or diagnosed with cancer within 5 years, received concurrent drugs that modulate glucose level or tolerance or affect the clearance of the study drugs. 


\subsection{Treatment protocol}

Study populations were divided randomly into 6 groups (30 persons/ group) for treatment with control (under moderately calorie-restricted diet and an active lifestyle), gliclazide $80 \mathrm{mg} /$ daily, metformin $500 \mathrm{mg}$ twice daily, glimepiride $3 \mathrm{mg}$ daily, combination of gliclazide and metformin or combination of glimepiride and metformin. All the medicines were taken daily for 3 months. All patients were followed to evaluate treatment.

\subsection{Efficacy evaluations}

The primary efficacy parameters were the changes in: fasting plasma glucose (FPG); postprandial plasma glucose (PPG); and changes in levels of Hcy and HbA1c from initial to 3 months. The secondary endpoints were the changes in the following clinical measurements: folate level; vitamin B12 level; triglycerides; high density lipoprotein cholesterol (HDL); low density lipoprotein cholesterol (LDL); cholesterol and risk ratio.

Plasma were obtained after centrifugation for estimation of glucose (Zhou $\boldsymbol{e t}$ al., 1973), cholesterol (Richmond, 1973), triacylglycerol (Buccolo and David, 1973), HDLcholesterol (Assmann et al., 1983), LDL-cholesterol (Friedewald et al., 1972). HbA1c level were measured by fluorescent polarization enzymatic technique (Abbott Laboratories). Plasma level of Hyc was estimated using HPLC (Zhloba et al., 2004). Plasma levels of folic acid and vitamin B12 were measured using HPLC (Pavlos et al., 2004).

\subsection{Evaluation of safety}

All patients were monitored for any adverse events which were classified as drugrelated or not related to the drug under study. Adverse drug events imply any sickness, sign, symptom, or any marked laboratory test abnormality that happened or aggravated during the study period. The occurrence of hypoglycemia was proposed when the patient exhibits at least one specific symptom of hypoglycemia and then confirmed by laboratory measurement of plasma glucose concentration $<60 \mathrm{mg} / \mathrm{dl}$. Gastrointestinal side effects were settled as abdominal pain, diarrhea, and nausea or vomiting. Sever adverse reactions were defined as any adverse events happening at any dose level that leaded to death, a life threatening problem, inpatient hospitalization, or other important medical case that required obligatory medical or surgical management to prevent mortality or permanent morbidity.

\subsection{Statistical analysis}

Only patients who completed the whole study period were compiled in the final statistical calculation. Parametric data were presented as mean and standard error of the mean, and nominal data were reported as percentage. All statistical analyses were 2-sided and the probability of 0.05 was taken as level of significance. Student's t test was used to compare intragroup differences before and after treatment, however ANOVA test was used to analyze changes along the whole study followed by Tukey's post hoc test for multiple comparisons. GraphPad InStat 3 (GraphPad Software, Inc. La Jolla, CA, USA) was used to perform all statistical analysis.

\section{RESULTS}

\subsection{Characteristics of study population}

There were no significant differences in any demographic or clinical and laboratory characteristics between groups at baseline (Table 1).

\subsection{Effect of treatment on blood glucose level}

In contrast to baseline data, there are significant differences among treatment groups 3 months post treatment. The combination of gliclazide or glimepiride with metformin 
significantly decreased FPG, PPG levels and HbA1C compared to control-diabetic group and metformin monotherapy group (table 2). The greatest decreases were achieved with glimepiride plus metformin group.

There are no significant differences between gliclazide/ metformin and glimepiride/metformin groups concerning changes from initial baseline to the end of the treatment in fasting $(-26.1 \% \pm 3.7$ vs. $-28.9 \pm 3.1)$ and postprandial glucose $(-42.4 \% \pm 3.3$ vs. $-46 \pm 2.6)$ and $\mathrm{HbA} 1 \mathrm{C}$ concentration $(-21.1 \pm 1.5$ vs. $-21.3 \pm 1.6 \%)$, table 3 .

\subsection{Effects of different treatments on homocysteine, vitamin $B 12$ and folic acid levels}

Interestingly, there are significant differences among treatment groups in the levels of Hcy, vitamin B12 and folate, 3 months post treatment (table 4). Metformin induced significant elevation in plasma Hcy level $(12.3 \pm 0.3)$, with concurrent decrease in levels of Vit B12 (326 \pm 8$)$ and folate $(11.4 \pm 0.3)$ compared to control diabetic group. Similar results with little degree were obtained up on treatment with gliclazide alone. However glimpiride alone did not exhibit any significant change compared to diabetic control group in these parameters. Most important, addition of either gliclazide or glimipride to metformin ameliorated metformin induced disturbance in levels of Hcy, Vitamin B12 and folate (Table 4). The values exhibited by combination of glimepiride with metformin were $10.3 \pm 0.3 ; 378$ $\pm 12 ; 15 \pm 0.9$ which were superior to the results of combination of gliclazide and metformin $11 \pm 0.3 ; 366 \pm 10 ; 13.9 \pm 0.5$ for Hcy level, vitamin B12 level and serum folate level respectively (table 4 ).

Comparing changes to corresponding baseline values, metformin induced a $29.5 \%$ increase in Hcy level $(\mathrm{P}<0.01), 20 \%$ and 35\% decrease in vitamin B12 and folate levels respectively $(\mathrm{P}<0.01)$. Combination of metformin with gliclazide ameliorated these effects (10\% increase in Hcy; 9\% decrease in vitamin B12 and $17.8 \%$ decrease in folate level). However addition of glimepiride to metformin bought these parameters close to the base line values (5.6\% increase in Hcy; 6.9\% decrease in Vitamin B12 and $11.8 \%$ decrease in folate level) table 5.

\subsection{Lipid profile results}

Metformin induced non significant disturbance in lipid profile while gliclazide alone and glimepiride alone led to improvement of the lipid profile during the treatment period (3 months) compared to diabetic control. A combination of glimepiride or gliclazide with metformin improved lipid levels. With particular interest, combination of glimepiride with metformin significantly decreased total cholesterol and significantly increased high density lipoprotein (HDL) level and hence significantly decreased the risk ratio compared to both control diabetic group and metformin treated group (table 6).

\subsection{Safety study}

Metformin, gliclazide and glimepiride were tolerated by all patients. Only two patients $(6.6 \%)$, from each group treatment with either gliclazide or glimepiride monotherapy developed symptomatic hypoglycemia. In contrast, none of patients that used metformin developed any symptoms of hypoglycemia. During combination therapy, symptomatic hypoglycemia occurred in 3 of $30(10 \%)$ patients treated with metformin and gliclazide, in 5 of $30(16.6 \%)$ patients who were treated with metformin plus glimepiride. The reported hypoglycemic attacks were mild and did not happen after improvement of dietary intake. GI side-effects occurred more frequently in metformin- treated patients than both sulfonylurea drug sole therapy $(10 \%$ metformin group versus $6 \%$ in gliclazide group and $0 \%$ in glimepride group) and combination therapy (10\% with metformin and gliclazide, $6 \%$ with metformin plus glimepiride). No patients discontinued the therapy due to side-effects. 
Table 1: Clinical and laboratory variables for patients before treatment

\begin{tabular}{|c|c|c|c|c|c|c|c|}
\hline & Control & Metformin & Gliclazide & Gliclazide + Metformin & Glimepiride & Glimepiride + Metformin & $P$ value \\
\hline FPG (mg/dl) & $203 \pm 7$ & $204 \pm 7.5$ & $199 \pm 9$ & $203 \pm 8$ & $194 \pm 8.5$ & $197 \pm 8$ & 0.93 \\
\hline PPG (mg/dl) & $270 \pm 10$ & $272 \pm 9$ & $267 \pm 9.5$ & $269 \pm 11$ & $271 \pm 8$ & $269.5 \pm 7$ & 0.993 \\
\hline HbA1C (\%) & $9 \pm 0.5$ & $8.9 \pm 0.4$ & $8.9 \pm 0.5$ & $9 \pm 0.4$ & $8.8 \pm 0.4$ & $8.9 \pm 0.5$ & 0.999 \\
\hline $\begin{array}{l}\text { Serum Hcy } \\
(\mathrm{pmol} / \mathrm{L})\end{array}$ & $10 \pm 0.2$ & $9.5 \pm 0.3$ & $9.5 \pm 0.5$ & $10 \pm 0.2$ & $10 \pm 0.3$ & $9.75 \pm 0.4$ & 0.744 \\
\hline Vit B12 (pmol/L) & $405 \pm 10$ & $407 \pm 12$ & $403 \pm 8$ & $402 \pm 12$ & $403 \pm 15$ & $406 \pm 14$ & 0.999 \\
\hline $\begin{array}{l}\text { Serum Folate } \\
(\mathrm{nmol} / \mathrm{L})\end{array}$ & $17 \pm 1.2$ & $17.5 \pm 1.5$ & $17.2 \pm 0.9$ & $16.9 \pm 0.7$ & $16.5 \pm 1$ & $17 \pm 1.3$ & 0.994 \\
\hline $\begin{array}{l}\text { Total cholesterol } \\
(\mathrm{mg} / \mathrm{dl})\end{array}$ & $235 \pm 15$ & $237 \pm 12$ & $234 \pm 17$ & $237 \pm 12$ & $235.5 \pm 13$ & $233 \pm 15$ & 0.999 \\
\hline HDL (mg/dl) & $40 \pm 2$ & $41 \pm 1.5$ & $41.5 \pm 1.3$ & $38 \pm 1.7$ & $39 \pm 2.5$ & $39.5 \pm 1.4$ & 0.756 \\
\hline LDL (mg/dl) & $143 \pm 5$ & $144 \pm 7$ & $141 \pm 7$ & $148 \pm 8$ & $147 \pm 5$ & $142 \pm 6$ & 0.966 \\
\hline $\begin{array}{l}\text { Triglycerides } \\
\text { (mg/dl) }\end{array}$ & $257 \pm 10$ & $257 \pm 13$ & $256 \pm 15$ & $258 \pm 17$ & $249 \pm 11$ & $258 \pm 15$ & 0.997 \\
\hline $\begin{array}{l}\text { Risk ratio } \\
(\mathrm{TC} / \mathrm{HDL})\end{array}$ & $5.8 \pm 0.2$ & $5.8 \pm 0.3$ & $5.6 \pm 0.3$ & $6.2 \pm 0.2$ & $6 \pm 0.1$ & $5.9 \pm 0.4$ & 0.714 \\
\hline BMI $\left(\mathrm{kg} / \mathrm{m}^{2}\right)$ & $27 \pm 2.5$ & $27.6 \pm 2.4$ & $28.1 \pm 1.8$ & $27.3 \pm 2.3$ & $27.5 \pm 1.9$ & $28 \pm 2.7$ & 0.999 \\
\hline
\end{tabular}

- Data are presented as mean \pm standard error of 30 patients per group

- FPG: fasting plasma glucose; PPG: postprandial plasma glucose; HbA1C: glycosylated hemoglobin; Hcy: homocysteine; BMI: body mass index ; LDL : lowdensity lipoprotein; HDL: high-density lipoprotein 
Table 2: Effects of different treatment protocols on plasma glucose and glycosylated hemoglobin levels.

\begin{tabular}{|l|c|c|c|c|c|c|}
\hline & Control & Metformin & Gliclazide & Gliclazide + Metformin & Glimepride & Glimepride + Metformin \\
\hline FPG $(\mathrm{mg} / \mathrm{dl})$ & $210 \pm 6$ & $180 \pm 4^{\mathrm{a}}$ & $166 \pm 7^{\mathrm{a}}$ & $150 \pm 5^{\mathrm{a}, \mathrm{b}}$ & $165 \pm 7^{\mathrm{a}}$ & $140 \pm 5^{\mathrm{a}, \mathrm{b}, \mathrm{c}, \mathrm{e}}$ \\
\hline PPG $(\mathrm{mg} / \mathrm{dl})$ & $280 \pm 10$ & $186 \pm 7^{\mathrm{a}}$ & $166 \pm 5^{\mathrm{a}}$ & $155 \pm 5^{\mathrm{a}, \mathrm{b}}$ & $160 \pm 6^{\mathrm{a}}$ & $145 \pm 7^{\mathrm{a}, \mathrm{b}}$ \\
\hline HbA1C $(\%)$ & $9.2 \pm 0.3$ & $8.2 \pm 0.2^{\mathrm{a}}$ & $7.7 \pm 0.1^{\mathrm{a}}$ & $7.1 \pm 0.2^{\mathrm{a}, \mathrm{b}}$ & $7.8 \pm 0.2^{\mathrm{a}, \mathrm{b}}$ & $7 \pm 0.1^{\mathrm{a}, \mathrm{b}}$ \\
\hline
\end{tabular}

- $\quad$ a,b,c,e are significant change from control, metformin, gliclazide and, glimepiride respectively at $\mathrm{p}<0.05$ using Tukey's test as post ANOVA test

- Type 2 diabetic patients were treated with placebo(control), metformin $500 \mathrm{mg}$ twice daily, gliclazide $80 \mathrm{mg} / \mathrm{daily}$, Glimepiride $3 \mathrm{mg} / \mathrm{daily}$, combination of gliclazide and metformin or combination of glimepride and metformin for 3 months

- Data are presented as mean \pm standard error of 30 patients per group

- FPG: fasting plasma glucose; PPG: postprandial plasma glucose; HbA1C : glycosylated hemoglobin

Table 3: Comparing plasma levels of glucose and glycosylated hemoglobin post treatment to their corresponding base line values

\begin{tabular}{|l|c|c|c|c|c|c|}
\hline & Control & Metformin & Gliclazide & Gliclazide + Metformin & Glimepiride & Glimepiride + Metformin \\
\hline FPG (\% of initial) & $103.4 \pm 2$ & $88.2 \pm 3^{\mathrm{a}}$ & $83.6 \pm 4^{\mathrm{a}}$ & $73.9 \pm 3.7^{\mathrm{a}}$ & $85.1 \pm 3^{\mathrm{a}}$ & $71.1 \pm 3.1^{\mathrm{a}}$ \\
\hline PPG (\% of initial) & $\begin{array}{c}103.7 \\
\pm 3.5\end{array}$ & $68.4 \pm 2.5^{\mathrm{a}}$ & $62.2 \pm 3^{\mathrm{a}}$ & $57.6 \pm 3.3^{\mathrm{a}}$ & $59 \pm 2.5^{\mathrm{a}}$ & $54 \pm 2.6^{\mathrm{a}}$ \\
\hline HbA1C $(\%$ of initial) & $102.2 \pm 2$ & $82.1 \pm 2$ & $-86.5 \pm 4^{\mathrm{a}}$ & $78.9 \pm 1.5^{\mathrm{a}}$ & $88.6 \pm 2^{\mathrm{a}}$ & $78.7 \pm 1.6^{\mathrm{a}}$ \\
\hline
\end{tabular}

- ${ }^{a}$ indicates significant difference from corresponding base line value, at $\mathrm{p}<0.5$, using two tailed student $\mathrm{t}$ test.

- Type 2 diabetic patients were treated with placebo( control), metformin $500 \mathrm{mg}$ twice daily, gliclazide $80 \mathrm{mg} / \mathrm{daily}$, Glimepride $3 \mathrm{mg} / \mathrm{daily}$, combination of gliclazide and metformin or combination of glimepride and metformin for 3 months

- Data are calculated as percentage of corresponding initial values (before treatment)

- Data are presented as mean \pm standard error of 30 patients per group

- $\quad$ FPG: fasting plasma glucose; PPG: postprandial plasma glucose; HbA1C : glycosylated hemoglobin 
Table 4: Effects of different treatments on plasma levels of homocysteine, vitamin B12 and folate.

\begin{tabular}{|l|c|c|c|c|c|c|}
\hline & Control & Metformin & Gliclazide & Gliclazide + Metformin & Glimepiride & Glimepiride + Metformin \\
\hline Hcy (pmol/L) & $9.6 \pm 0.2$ & $12.3 \pm 0.3^{\mathrm{a}}$ & $11.4 \pm 0.4^{\mathrm{a}}$ & $11 \pm 0.3^{\mathrm{a}}$ & $9 \pm 0.4^{\mathrm{b}, \mathrm{c}, \mathrm{d}}$ & $10.3 \pm 0.3^{\mathrm{b}, \mathrm{c}}$ \\
\hline Vit B12 (pmol/L) & $393 \pm 15$ & $326 \pm 8^{\mathrm{a}}$ & $388 \pm 9^{\mathrm{b}}$ & $366 \pm 10$ & $389 \pm 14^{\mathrm{b}}$ & $378 \pm 12^{\mathrm{b}}$ \\
\hline Folate (nmol/L) & $17.8 \pm 0.6$ & $11.4 \pm 0.3^{\mathrm{a}}$ & $14.3 \pm 0.6^{\mathrm{a}, \mathrm{b}}$ & $13.9 \pm 0.5^{\mathrm{a}}$ & $15.5 \pm 0.75^{\mathrm{b}}$ & $15 \pm 0.9^{\mathrm{a}, \mathrm{b}}$ \\
\hline
\end{tabular}

- $\quad \mathrm{a}, \mathrm{b}, \mathrm{c,d}$ indicate significant change from control, metformin, gliclazide and metformin + gliclazide respectively, at $\mathrm{p}<0.5$, using Tukey's test as post ANOVA test

- Type 2 diabetic patients were treated with placebo(control), metformin $500 \mathrm{mg}$ twice daily, gliclazide $80 \mathrm{mg} / \mathrm{daily}$, Glimepiride $3 \mathrm{mg} /$ daily, combination of gliclazide and metformin or combination of glimepiride and metformin for 3 months

- Data are presented as mean \pm standard error of 30 patients per group

- Hcy: homocysteine

Table 5: Plasma levels of homocysteine, vitamin B12 and folate as percentage of corresponding base line values

\begin{tabular}{|l|c|c|c|c|c|c|}
\hline & Control & Metformin & Gliclazide & Gliclazide + Metformin & Glimepiride & Glimepiride + Metformin \\
\hline Hcy (\% of initial) & $96.0 \pm 2$ & $129.5 \pm 3^{\mathrm{a}}$ & $120.0 \pm 2^{\mathrm{a}}$ & $110.0 \pm 2.5^{\mathrm{a}}$ & $90.0 \pm 4^{\mathrm{a}}$ & $105.6 \pm 4^{\mathrm{a}}$ \\
\hline Vit B12 (\% of initial) & $97.0 \pm 2.5$ & $80.1 \pm 3^{\mathrm{a}}$ & $96.3 \pm 3$ & $91.0 \pm 5^{\mathrm{a}}$ & $96.5 \pm 5$ & $93.1 \pm 5$ \\
\hline Folate (\% of initial) & $104.7 \pm 3$ & $65.1 \pm 4^{\mathrm{a}}$ & $83.1 \pm 3^{\mathrm{a}}$ & $82.2 \pm 6^{\mathrm{a}}$ & $93.9 \pm 5$ & $88.2 \pm 6$ \\
\hline
\end{tabular}

a ${ }^{\mathrm{a}}$ indicates significant difference from base line data using two tailed Student $\mathrm{T}$ test at $\mathrm{p}<0.05$.

- Type 2 diabetic patients were treated with placebo( control), metformin $500 \mathrm{mg}$ twice daily, gliclazide $80 \mathrm{mg} / \mathrm{daily}$, Glimepiride $3 \mathrm{mg} /$ daily, combination of gliclazide and metformin or combination of glimepiride and metformin for 3 months

- Data are presented as mean \pm standard error of 30 patients per group

- Data are calculated as percentage of corresponding initial values (before treatment)

- Hcy: homocysteine 
Table 6: Effects of different treatment protocols on plasma lipid profile.

\begin{tabular}{|l|c|c|c|c|c|c|}
\hline & Control & Metformin & Gliclazide & Gliclazide + Metformin & Glimepiride & Glimepiride + Metformin \\
\hline Total cholesterol (mg/dl) & $255 \pm 9$ & $260 \pm 13$ & $225 \pm 11^{\mathrm{a}, \mathrm{b}}$ & $235 \pm 8$ & $217 \pm 10^{\mathrm{a}, \mathrm{b}}$ & $212 \pm 12^{\mathrm{a}, \mathrm{b}}$ \\
\hline HDL (mg/dl) & $39 \pm 1.2$ & $36 \pm 1.9$ & $43 \pm 2.5$ & $39 \pm 1.3$ & $45 \pm 1.5^{\mathrm{a}, \mathrm{b}}$ & $44 \pm 1.6^{\mathrm{a}, \mathrm{b}}$ \\
\hline LDL (mg/dl) & $164 \pm 5$ & $168 \pm 10$ & $133 \pm 9^{\mathrm{a}, \mathrm{b}}$ & $146 \pm 7$ & $126 \pm 10^{\mathrm{a}, \mathrm{b}}$ & $142 \pm 7^{\mathrm{a}, \mathrm{b}}$ \\
\hline Triglycerides (mg/dl) & $261 \pm 12$ & $279 \pm 17$ & $244 \pm 13^{\mathrm{a}, \mathrm{b}}$ & $250 \pm 15$ & $235 \pm 12^{\mathrm{a}, \mathrm{b}}$ & $247 \pm 17^{\mathrm{a}, \mathrm{b}}$ \\
\hline Risk ratio (TC/HDL) & $6.5 \pm 0.5$ & $7.2 \pm 0.3$ & $5.2 \pm 0.2^{\mathrm{a}, \mathrm{b}}$ & $6 \pm 0.1$ & $4.8 \pm 0.3^{\mathrm{a}, \mathrm{b}}$ & $4.8 \pm 0.2^{\mathrm{a}, \mathrm{b}}$ \\
\hline
\end{tabular}

- $\quad \mathrm{a}, \mathrm{b}$ indicate significant change from control, metformin using Tukey's test as post ANOVA test at $\mathrm{p}<0.05$

- Type 2 diabetic patients were treated with placebo(control), metformin $500 \mathrm{mg}$ twice daily, gliclazide $80 \mathrm{mg} /$ daily, Glimepiride $3 \mathrm{mg} / \mathrm{daily}$, combination of gliclazide and metformin or combination of glimepiride and metformin for 3 months

- Data are presented as mean \pm standard error of 30 patients per group

- LDL : low-density lipoprotein; HDL: high-density lipoprotein 


\section{DISCUSSION:}

It has been established that combination therapy for diabetes is superior in hyperglycemic control in comparison to single agent therapy (U.K. Prospective Diabetes Study Group, 1998; Raz, 2013). In this study, we chose two common combinations; metformin plus gliclazide, and metformin plus glimepiride. These two metformin combinations utilize a second generation sulfonylurea and a third-generation sulfonylurea drugs, respectively (Müller et al., 1995). According to our knowledge, there is no currently available clinical information about the comparison of the effects mediated by the selected sulfonylureas drugs, at specific doses, and in combination with metformin on the cardiovascular risk factors.

It is important to address both limitations and merits of our study; one of the important limitations is non-equivalence of the selected combinations. On the other hand, this investigation utilized strict selection criteria, controlled and randomized design which solidify and trust its results. Note worthily this methodological strength has led to non significant difference among regarding clinical and laboratory basal characteristics (table 1).

In this study, both combination therapy groups exhibited significant decreases in all primary efficacy parameters; HbA1c, PPG, FPG and Hcy levels at the end of treatment compared to their corresponding baseline values. Serum folic acid and serum vitamin B12 were significantly increased at the end of therapy as compared with baseline values. Moreover, the lipid profile was also improved during the treatment period (tables 2-6). All patients tolerated the combination therapy without any reported major adverse effect.

It is an established knowledge that hyperglycemia augments the production of reactive oxygen species (ROS) by mitochondria, which plays a pivotal event in the development and progression of diabetes morbidity and even more induces; programmed cell death, glycation of several important proteins, in addition to glucose autoxidation (Wolff $\boldsymbol{e t}$ al., 1991; Nishikawa et al.. 2000; Park et al., 2001; Kiritoshi et al., 2003; Hamadi et al., 2012). Furthermore, ROS production could be a result of increased mitochondrial uncoupling and $\beta$-oxidation due disturbed high lipid profile (Wojtczak and Schonfeld, 1993; King and Loeken, 2004).

Our results showed significant lowering in FPG and PPG levels for both selected combinations used in our study, compared to both control and metformin groups. These results are in line with previous reports (Krentz and Bailey, 2005; American Diabetes Association, 2008). Interestingly, at the end of the study, combination treated groups showed significantly lower HbA1C levels than metformin sole therapy group. These results could be attributed to the higher decreases in FPG, PPG. Interestingly, glimepiride plus metformin showed better $\mathrm{HbA} 1 \mathrm{C}$ than gliclazide plus metformin which might be due to better glycemic control. It is worth mentioning that $\mathrm{HbA1C}$ is valuable indicator of good metabolic control, because it evaluates the contributions of both FPF and PPG concentrations and their versatility (Monnier et al., 2007).

Hyperhomocysteinemia is well known risky metabolic parameter for cardiovascular disorders (Munshi et al., 1996; Eikelboom et al., 1999; Stehouwer et al., 1999; Hoogeveen et al., 2000; Aghamohammadi et al., 2011). Metabolic disorders such as diabetes interact with Hyc metabolism and may thus contribute in the development of atherosclerosis seen in T2DM patients (Fonseca et al., 1999; Fonseca et al., 2003; Emoto et al., 2001). Of particular importance plasma Hcy level is affected by serum folic acid and vitamin B12 (Jacobsen, 1996). Thus diabetes control using drugs that could normalize metabolic 
parameters such as vitamin B12, folate level and Hyc level may prevent cardiovascular risk in diabetic patients.

The implication of higher Hcy level on cardiac toxicity possibly explained by induction of endothelial cell injury or dysfunction, increased growth of vascular smooth muscle cells, elevated platelet aggregation, augmented thromboxane biosynthesis, enhanced LDL oxidation, enhanced macrophage-derived tissue factor activity, deposition in the arterial wall, and direct activation of the coagulation cascade leading to enhanced risk of thrombosis (Palareti et al., 1986; Rodgers and Kane ,1986; Fryer et al., 1993; Nishinaga et al. 1993; Majors et al., 1997; Thambyrajah and Townend, 2000).

Hcy level was decreased in combination groups possibly due to elevation of serum folate level and Vit B12 level (Naurath et al., 1995; Jacobsen, 1996; Aghamohammadi et al., 2011).

It is well documented that hyperglycemia is accompanied with lipid profile disturbance manifested as increased total cholesterol (TC), triglyceride (TG), LDL levels and decreased HDL level (Taskinen, 2002; Zhou et al., 2008; Hamadi et al., 2012), which is considered as high risk factor for several complications, specially for diabetic patient, such as atherosclerosis and myocardial infarction (Arvind et al., 2002; Taskinen, 2002). Lipid peroxidation generates endogenous toxicants resulted in excessive tissue damage and functional abnormalities via interaction of DNA and important proteins (Arvind $\boldsymbol{e t}$ al., 2002; Taskinen, 2002; Sahreen et al., 2011). Metformin induced non significant disturbance in the lipid profile in diabetic patient and increase in the risk ratio which might lead to serious effects on the heart (Hoogeveen et al., 2000; Arvind et al., 2002; Taskinen, 2002). A combination of glimepiride or gliclazide with metformin improved lipid levels. Note northerly, combination of glimepiride with metformin was better in achieving better lipid profile compared even to control diabetic group. This effect might be ascribed to better glycemic control, decreased \% HbA1C and decreased Hcy level achieved by combination of glimepiride with metformin.

\section{CONCLUSIONS}

Metformin induced significant elevation in homocysteine level and decrease in folic acid and vitamin B12 level with concomitant non significant disturbance in the lipid profile.

The addition of gliclazide or glimepiride to metformin is an effective modality to reach better glycemic control via improving FPG, PPG and HbA1C levels. Glimepiride plus metformin showed better glycemic control than gliclazide metformin combination. In addition, combination of glimepiride with metformin alleviated the cardiovascular risk factors via improving lipid levels, Hcy level, and vitamin B12 and folic acid levels with safe tolerability profile while combination of gliclazide plus metformin fail to exhibit significant changes on these parameters compared to metformin alone.

Glimepiride plus metformin was superior to gliclazide plus metformin combination and metformin alone in decreasing cardiovascular risk factors in uncontrolled T2DM patients.

\section{ACKNOWLEDGMENTS}

\section{Declaration of Conflicting Interests}

The authors declared no potential conflicts of interest with respect to the research, authorship, and/or publication of this article. 


\section{Funding}

The authors received no financial support for the research, authorship, and/or publication of this article.

\section{REFERENCES}

Aghamohammadi V, Gargari BP and Aliasgharzadeh $A$ (2011): Effect of folic acid supplementation on homocysteine, serum total antioxidant capacity, and malondialdehyde in patients with type 2 diabetes mellitus. J. Am. Coll. Nutr., 30(3): 210-215.

Alberti KG, and Zimmet PZ (1998): Definition, diagnosis and classification of diabetes mellitus and its complications. Part 1: Diagnosis and classification of diabetes mellitus provisional report of a WHO consultation. Diabet Med. , 15: 539-553.

American Diabetes Association (2008): Standards of medical care in diabetes-2008. Diabetes Care, 31: S12-S54.

Arvind K, Pradeepa R, Deepa $R$ and Mohan V (2002): Diabetes \& coronary artery disease. Ind. J. Med. Res., 116: 163-176.

Assmann, G., H. Schriewer, G. Schmltz and E.Hagele, (1983): Quantification of high densitylipoprotein cholesterol by precipitation with phosphotungestic acid / $\mathrm{MgCl}$ . Clin Chem, 29(12):2026 - 30.

Bell DSM (2006): Do sulfonylurea drugs increase the risk of cardiac events? CMAJ, 174: $185-186$.

Buccolo, G. and H. David, (1973): Quantitative determination of triglycerides by the use of enzymes. Clin. Chem., 19(5): 476 - 82.

Cefalu WT (2005): Glycemic control and cardiovascular disease - should we reassess clinical goals? N. Engl. J. Med., 353: 2707-2708.

Dailey $G E$ (2003): Glyburide/metformin tablets: A new therapeutic option for the management of type 2 diabetes. Expert. Opin. Pharmacother., 4: 1417-1430.

DeFronzo RA (1999): Pharmacologic therapy for type 2 diabetes mellitus. Ann. Intern. Med., 131: 281-303.

Eikelboom JW, Lonn E, Genest J, Jr, Hankey G, and Yusuf S (1999): Homocyst(e)ine and cardiovascular disease: A critical review of the epidemiologic evidence. Ann. Intern. Med., 131: 363-375.

Emoto M, Kanda H, Shoji T, Kawagishi T, Komatsu M, Mori K, Tahara H, Ishimura E, Inaba M, Okuno Y, and Nishizawa Y (2001): Impact of insulin resistance and nephropathy on homocysteine in type 2 diabetes. Diabetes Care, 24: 533- 538.

Erle G, Lovise S, Stocchiero C, Lora L, Coppini A, Marchetti P and Merante DA (1999): comparison of preconstituted, fixed combinations of low-dose glyburide plus metformin versus high-dose glyburide alone in the treatment of type 2 diabetic patients. Acta Diabetol., 36:61-65.

Friedewald, W., R. Levy and D. Fredrickson,(1972): Estimation of low density lipoprotein cholesterol in plasma without use of the preparative ultracentrifuge. Clin. Chem., 18(6): 499- 502. 
Fonseca VA, Fink LM, and Kern PA (2003): Insulin sensitivity and plasma homocysteine concentrations in non-diabetic obese and normal weight subjects. Atherosclerosis, 167 (1): 105-109.

Fonseca V, Guba SC and Fink LM (1999): Hyperhomocysteinemia and the endocrine system: Implications for atherosclerosis and thrombosis. Endocrine Reviews, 20: $738-759$

Fryer RH, Wilson BD, Gubler DB, Fitzgerald LA and Rodgers GM (1993): Homocysteine, a risk factor for premature vascular disease and thrombosis, induces tissue factor activity in endothelial cells. Arterioscler Thromb., 13: 1327-33.

Haffner SM, Lehto S, Ronnemaa T, Pyo" ra“ la“ K and Laakso M (1998): Mortality from coronary heart disease in subjects with type 2 diabetes and in nondiabetic subjects with and without prior myocardial infarction. N. Engl. J. Med. ,339: 229-234.

Hamadi N, Mansour A, Hassan MH, Khalifi-Touhami F and Badary $O$ (2012): Ameliorative effects of resveratrol on liver injury in streptozotocin-induced diabetic rats. J. Biochem. Mol. Toxicol., 26(10):384-92

Hermann LS, Schersten B and Melander A (1994): Antihyperglycaemic efficacy, response prediction and dose-response relations of treatment with metformin and sulphonylurea, alone and in primary combination. Diabet. Med., 11:953-960.

Holman RR, Paul SK, Bethel MA, Matthews DR and Neil HA (2008): 10-year follow-up of intensive glucose control in type 2 diabetes. N. Engl. J. Med., 359:1577-1589

Hoogeveen EK, Kostense PJ, Jakobs C, Dekker JM, Nijpels G, Heine RJ, Bouter LM, and Stehouwer CD (2000): Hyperhomocysteinemia increases risk of death, especially in type 2 diabetes: 5-year follow-up of the Hoorn Study. Circulation, 101: 15061511 .

Jacobsen DW (1996): Determinants of hyperhomocysteinemia: A matter of nature and nurture. Am. J. Clin. Nutr., 64:641-642.

King GL and Loeken MR (2004): Hyperglycemia-induced oxidative stress in diabetic complications. Histochem. Cell Biol., 122:333-338.

Kiritoshi S, Nishikawa T, Sonoda K, Kukidome D, Senokuchi T, Matsuo T, Matsumura T, Tokunaga H, Brownlee $M$ and Araki E (2003): Reactive oxygen species from mitochondria induce cyclooxygenase- 2 gene expression in human mesangial cells: potential role in diabetic nephropathy. Diabetes, 52: 2570-2577.

Krentz AJ and Bailey CJ (2005): Oral antidiabetic agents: Current role in type 2 diabetes mellitus. Drugs, 65: 385-411.

Majors A, Ehrhart LA and Pezacka EH (1997): Homocysteine as a risk factor for vascular disease. Enhanced collagen production and accumulation by smoothmuscle cells. Arterioscler Thromb. Vasc. Biol., 17(10): 2074-81.

Monnier L, Colette C, Dunseath GJ, and Owens DR (2007): The loss of postprandial glycemic control precedes stepwise deterioration of fasting with worsening diabetes. Diabetes Care, 30: 263-269.

Müller G, Satoh $Y$ and Geisen $K$ (1995): Extrapancreatic effects of sulfonylureas-A comparison between glimepiride and conventional sulfonylureas. Diabetes Res. Clin. Pract., 28(Suppl): S115-S137. 
Munshi MN, Stone A, Fink L, and Fonseca V (1996): Hyperhomocysteinemia following a methionine load in patients with non-insulin-dependent diabetes mellitus and macrovascular disease. Metabol., 45: 133- 135.

Nathan DM, Buse JB, Davidson MB, Ferrannini E, Holman RR, Sherwin R and Zinman B (2009): American Diabetes Association; European Association for the Study of Diabetes. Medical management of hyperglycaemia in type 2 diabetes mellitus: a consensus algorithm for the initiation and adjustment of therapy: a consensus statement from the American Diabetes Association and the European Association for the Study of Diabetes. Diabetologia, 52:17-30

Naurath HJ, Joosten E, Riezler R, Stabler SP, Allen RH, and Lindenbaum J (1995): Effects of vitamin B12, folate, and vitamin B6 supplements in elderly people with normal serum vitamin concentrations. Lancet, 346: 85-89.

Nishikawa T, Edelstein D, Du XL, Yamagishi S, Matsumura T, Kaneda Y, Yorek MA, Beebe D, Oates PJ, Hammes HP, Giardino I and Brownlee M (2000): Normalizing mitochondrial superoxide production blocks three pathways of hyperglycaemic damage. Nature, 404: 787-790.

Nishinaga M, Ozawa T and Shimada K (1993): Homocysteine, a thrombogenic agent, suppresses anticoagulant heparan sulfate expression in cultured porcine aortic endothelial cells. J. Clin. Invest., 92: 1381-6.

Palareti G, Salardi S, Piazzi S, Legnani C, Poggi M, Grauso F, Caniato A, Coccheri S and Cacciari $\boldsymbol{E}$ (1986): Blood coagulation changes in homocystinuria: effects of pyridoxine and other specific therapy. J. Pediatr., 109: 1001-1006.

Park KS, Kim JH, Kim MS, Kim JM, Kim SK, Choi JY, Chung MH, Han B, Kim SY and Lee HK (2001): Effects of insulin and antioxidant on plasma 8hydroxyguanine and tissue 8-hydroxydeoxyguanosine in streptozotocin-induced diabetic rats. Diabetes, 50: 2837-2841.

Pavlos F, Chatzimichalakis V, Samanidou F, Robert V and Ioannis N, (2004): Development of a validated HPLC method for the determination of B-complex vitamins in pharmaceutical and biological fluids after solid phase extraction. $J$. Sep. Sci., 27: 1181.

$\boldsymbol{R a z} I$ (2013): Guideline approach to therapy in patients with newly diagnosed type 2 diabetes. Diabetes Care, 36: S139-44.

Rendell M (2004): The role of sulphonylureas in the management of type 2 diabetes mellitus. Drugs, 64: 1339-1358.

Richmond, W., (1973): Preparation and properties of cholesterol oxidase from nocardia Sp. and its application to enzymatic assay of total cholesterol in serum. Clin. Chem., 19(12): 1350 - 6.

Rodgers GM and Kane WH (1986): Activation of endogenous factor V by a homocysteineinduced vascular endothelial cell activator. J. Clin. Invest., 77: 1909-1916.

Sahin M, Tutuncu NB, Ertugrul D, Tanaci N and Guvener ND (2007): Effects of metformin or rosiglitazone on serum concentrations of homocysteine, folate, and vitamin B12 in patients with type 2 diabetes mellitus. J. Diabetes Complications, 21(2): 118-23. 
Sahreen S, Khan MR and Khan RA (2011): Hepatoprotective effects of methanol extract of Carissa opaca leaves on CCl4-induced damage in rat. BMC Complement. Altern. Med., 11:48.

Stehouwer CD, Gall MA, Hougaard P, Jakobs C and Parving HH (1999): Plasma homocysteine concentration predicts mortality in noninsulin- dependent diabetic patients with and without albuminuria. Kidney Int., 55: 308-314.

Taskinen MR (2002): Diabetic dyslipidemia. Atherosclerosis. Suppl., 3: 47-51

Thambyrajah J, and Townend JN (2000): Homocysteine and atherothrombosis mechanisms for Injury. Eur. Heart J., 21: 967-974.

Tomkin G, Hadden D, Weaver J, and Montgomery D (1971): Vitamin- B12 status of patients on long-term metformin therapy. Br. Med. J., 2: 685-687.

U.K. Prospective Diabetes Study Group. (1998): UKPDS 28: A randomized trial of efficacy of early addition of metformin in sulfonylurea-treated type 2 diabetes. Diabetes Care, 21: 87-92.

Waugh J, Keating GM, Plosker GL, Easthope S and Robinson DM (2006): Spotlight on pioglitazone in type 2 diabetes mellitus.Treat Endocrinol., 5(3):189-191.

WHO/IDF Consultation report (2006): Definition and diagnosis of diabetes mellitus and intermediate hyperglycemia. Report of a WHO/IDF Consultation: 1-50

Wojtczak $L$ and Schonfeld $P$ (1993): Effect of fatty acids on energy coupling processes in mitochondria. Biochim. Biophys. Acta. , 1183: 41-57.

Wolff SP, Jiang ZY and Hunt JV (1991): Protein glycation and oxidative stress in diabetes mellitus and ageing. Free Rad. Biol. Med.,10: 339-352.

Wulffele MG, Kooy A, Lehert P, Bets D, Ogterop JC, Borger van der Burg B, Donker AJ and Stehouwer $C D$ (2003): Effects of shortterm treatment with metformin on serum concentrations of homocysteine, folate and vitamin B12 in type 2 diabetes mellitus: A randomized, control-controlled trial. J. Int. Med., 254 (5): 455-463.

Zhloba A, Lexander A and Blashko E L (2004): Liquid chromatographic determination of total homocysteine in blood plasma with photometric detection. $J$. of chromatography B, 800: 275-280.

Zhou JY, Zhou SW, Zhang KB, Tang JL, Guang LX, Ying Y, Xu Y, Zhang L and Li DD (2008): Chronic effects of berberine on blood, liver glucolipid metabolism and liver PPARS expression in diabetic hyperlipidemic rats. Biol. Pharm. Bull., 31(6): 1169-1176.

Zhou, M.; Diwu, Z.; Panchuk-Voloshina, N.,and Haugland, R.P.(1997): A stable nonfluorescent derivative of Resorufin for the fluorometric determination of trace hydrogen peroxide: applications in detecting the activity of phagocyte NADPH oxidase and other oxidases. Anal Biochem., 15; 253(2):162-168 
آثار ميتفورمين و جليكلازيد مقابل ميتفورمين و جليمبرايد على عوامل الخطر القلبية الوعائية في

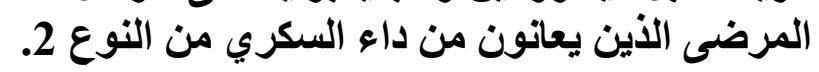

جميل محمل عبد الله 1 - ميمى حجازى حسن من داعن 2

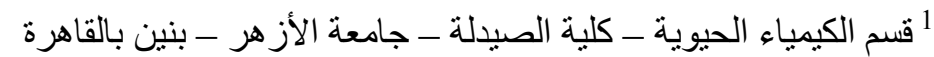

2 قسم علم الادوية و السموم - "كلية الصبيدلة - جامعة الأزيلة هر - بنين بالقاهرة

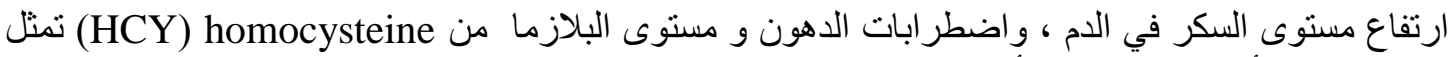

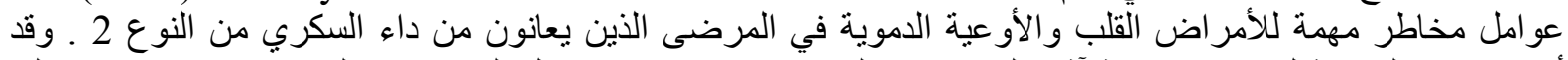

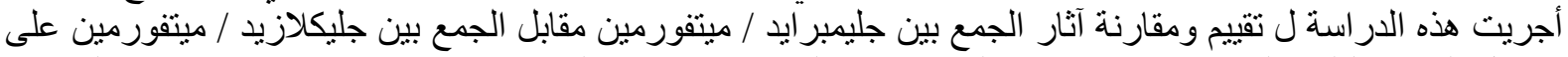

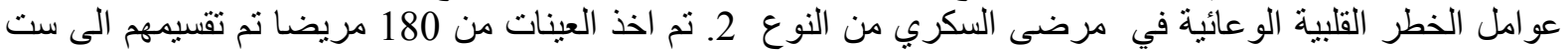

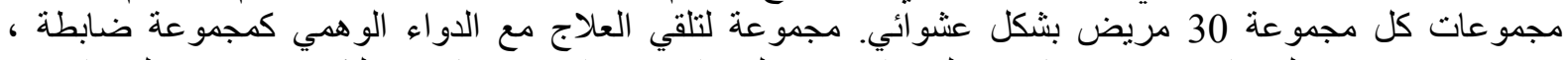

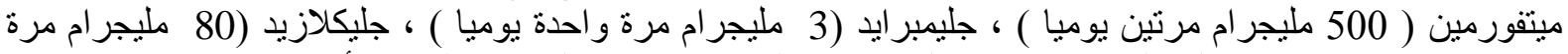

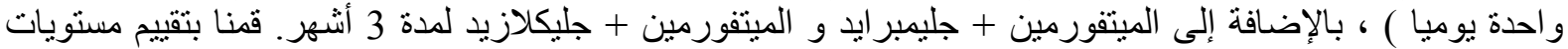

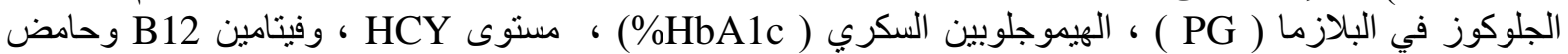

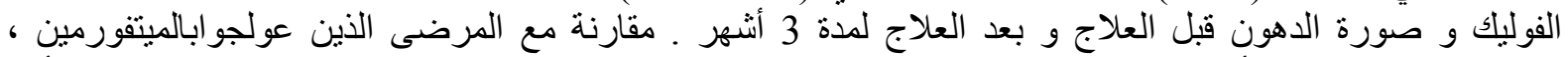

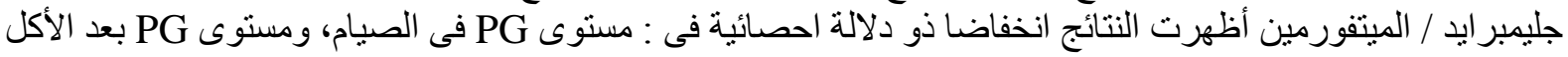

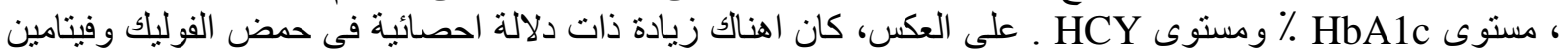

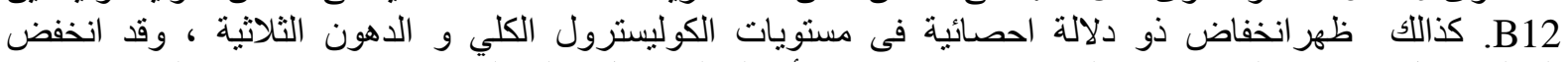

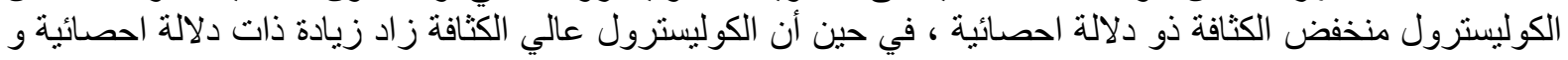

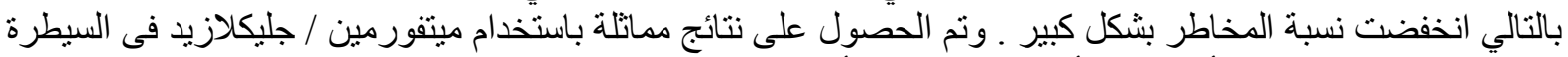

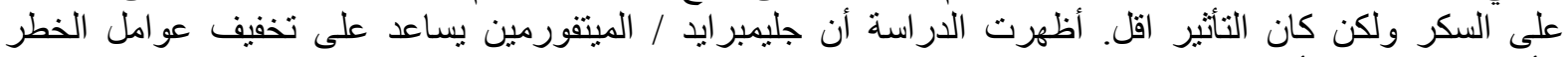

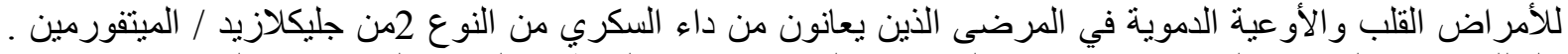

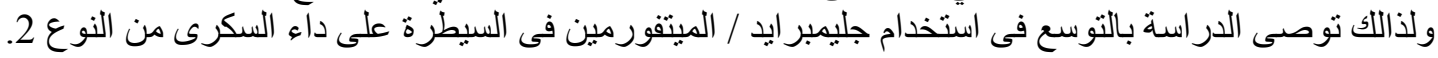


